\title{
Dengue: transmissão, aspectos clínicos, diagnóstico e tratamento
}

\section{Dengue: transmission, clinical features, diagnosis and treatment}

\author{
Larissa B. A. Dias ${ }^{1}$, Sérgio C.L. de Almeida ${ }^{2,3,4}$, Tissiana M.de Haes ${ }^{1,5}$, Letícia M. Mota ${ }^{6}$, Jarbas S Roriz-Filho ${ }^{2,7}$
}

\begin{abstract}
RESUMO
A dengue é uma arbovirose transmitida principalmente pela picada do mosquito Aedes aegypti. Pode ser assintomática ou apresentar amplo espectro clínico, variando de doença febril autolimitada até formas graves, que podem evoluir com choque circulatório e óbito. Para evitar esse desfecho, a precocidade no diagnóstico da doença e na detecção de sinais de alarme, que indicam evolução desfavorável; assim como a instituição de tratamento adequado, são fundamentais. Não há tratamento específico, ele é apenas sintomático e de suporte. Até o momento, não existe vacina disponível para prevenção da doença, sendo o controle do vetor a medida mais efetiva.
\end{abstract}

Palavras-chave: Vírus da Dengue. Febre Hemorrágica da Dengue. Flavivirus.

\section{Introdução}

Nos últimos anos, a dengue se tornou um problema de saúde pública. Isso devido ao grande número de casos da doença, fazendo dela a mais frequente das arboviroses que acomete o ser humano. A morbidade ocasionada, já que a intensa mialgia e prostração podem levar o doente ao afastamento das suas atividades produtivas por dias, associado a sua mortalidade, podem ser elevadas dependendo da forma da doença e da precocidade e eficácia do tratamento médico instituído. ${ }^{1}$
É transmitida principalmente por meio da picada do mosquito Aedes aegypti, apesar de haver outra espécie, o Aedes albopictus, que possui morfologia e capacidade proliferativa semelhantes ao anterior e também é responsável por alguns surtos da doença em países do continente asiático. ${ }^{2}$ No Brasil, o Aedes albopictus foi introduzido aproximadamente em 1980 , mas até o momento não foi identificado nenhum exemplar infectado pelo vírus da dengue. ${ }^{3}$

Existem relatos na literatura de transmissão vertical do vírus. Estudo realizado na Malásia com 2.531 gestantes mostrou prevalência de dengue durante a
1 Médico Assistente da Clínica Médica do Hospital Estadual de Ribeirão Preto.

2 Ex-Médico Assistente da Clínica Médica do Hospital Estadual de Ribeirão Preto.

3 Mestre em Clínica Médica pela Área de Clínica Médica da FMRPUSP.

4 Pós-graduando da Área de Clínica Médica da FMRP-USP. 5 Pós-graduanda da Área de Neurologia da FMRP-USP

6 Ex-Médica Assistente do Serviço de Controle de Infecção Hospitalar do Hospital Estadual de Ribeirão Preto.

7 Docente da Faculdade de Medicina da Universidade de Fortaleza (CE)
Correspondência Larissa Barbiero de Almeida Dias Hospital Estadual de Ribeirão Preto Avenida Independência, 4750 14026-160- Ribeirão Preto - SP Telefone: 16-3602-7100 
gestação de $2,5 \%$, com taxa de transmissão vertical de 1,6\%. ${ }^{4}$ Não foi identificada alteração significativa durante a gestação das mulheres infectadas em relação as não infectadas, apesar de este resultado ser controverso por haver outros estudos mostrando maior prevalência de complicações como morte fetal, baixo peso ao nascer e prematuridade. Ainda é necessário, portanto, novos estudos sobre a repercussão materna e fetal da infecção pela dengue durante a gestação. $^{4}$

É uma doença sazonal, ocorrendo com maior frequência em períodos quentes e de alta umidade, já que tais condições favorecem a proliferação do mosquito transmissor.

\section{Epidemiologia}

No Brasil, a primeira epidemia documentada clínica e laboratorialmente ocorreu entre 1981-1982 em Boa Vista, Roraima. ${ }^{5}$

Em 1986-1987 uma epidemia de grandes proporções assolou a cidade do Rio de Janeiro. A partir daí, novas epidemias ocorreram em diversos estados. ${ }^{5}$

Em 2002 ocorreu uma das maiores incidências da doença no Brasil, com quase 700.000 casos notificados. Depois disso, houve diminuição significativa do número de casos da doença em 2003 e 2004, voltando a aumentar em 2005.

Em 2010, até o início do mês de julho, foram detectados 789.055 casos suspeitos de dengue no país, representando aumento de mais de $150 \%$ em relação ao mesmo período de 2009. Desse total, 2.271 casos foram de Febre Hemorrágica da Dengue (FHD), com 367 óbitos. A região sudeste foi a que notificou o maior número de casos $(51,2 \%)$, seguida do Centro-Oeste $(23,7 \%)$, Nordeste $(11,3 \%)$, Norte $(8,5 \%)$ e Sul $(5,3 \%){ }^{6}$

\section{Virologia}

$O$ vírus da dengue pertence ao gênero Flavivirus e à família Flaviviridae. É um vírus RNA, de filamento único, envelopado e que possui quatro sorotipos: DEN-1, DEN-2, DEN-3 e DEN-4. ${ }^{7}$

A proteção cruzada entre eles é apenas transitória, de forma que uma mesma pessoa pode apresentar a doença até quatro vezes ao longo da sua vida. ${ }^{3}$

Pode haver coexistência de diferentes sorotipos em uma mesma região, o que aumenta a chance de se ter complicações como a febre hemorrágica da dengue. $^{3}$
No Brasil, o sorotipo 3 do vírus da dengue predominou na grande maioria dos estados entre 2002 e 2006. No período entre 2007 e 2009, observou-se alteração no sorotipo predominante, com a substituição do DEN-3 pelo DEN-2. Essa alteração levou a ocorrência de epidemias em diversos estados e ao aumento no número de casos graves da doença. Ao longo de 2009 ocorreu nova mudança no sorotipo predominante, com circulação importante do DEN-1, o que pode ser um dos fatores envolvidos no aumento da incidência em 2010, considerando a baixa circulação desse sorotipo ao longo dessa década. ${ }^{6}$

Em 2010, o sorotipo 4, que há 28 anos não circulava no Brasil, foi isolado em Roraima. A reintrodução desse sorotipo no país foi atribuída ao vírus proveniente da Venezuela, onde ele é endêmico há anos. Ainda não se sabe se esse agente terá força de transmissão em nosso território. ${ }^{8}$

\section{Vetor}

O Aedes aegypti é um mosquito de hábito diurno, principalmente no início da manhã e no final da tarde; tem preferência por ambientes urbanos e intradomiciliares; e alimenta-se principalmente de sangue humano. $^{3}$

A proliferação do mosquito é feita pela postura de ovos pela fêmea em coleções de água parada onde posteriormente eles eclodem originando as larvas. $\mathrm{O}$ tempo decorrido entre a eclosão do ovo e o mosquito adulto é cerca de 10 dias, sendo influenciado por fatores como a temperatura, que acelera esse processo. O ovo do mosquito sobrevive por até um ano fora da água, aguardando condições ambientais favoráveis para se desenvolver. ${ }^{3}$

\section{Transmissão e patogênese}

O mosquito adquire o vírus ao se alimentar do sangue de doente que se encontra na fase de viremia, que começa um dia antes do surgimento da febre e vai até o sexto dia de doença. $O$ vírus vai se localizar nas glândulas salivares do mosquito, onde se prolifera e aí permanece, deixando o artrópode infectante durante toda a sua vida. ${ }^{5}$ Uma vez infectada a fêmea do mosquito inocula o vírus junto com a sua saliva ao picar a pessoa sadia. Além disso, a fêmea também faz a transmissão transovariana do vírus para a sua prole, favorecendo a expansão da doença. ${ }^{3}$

Depois de inoculado no hospedeiro humano, o vírus entra nas células, se replica, produz progenitores 
virais e se inicia, então, a fase de viremia, com posterior distribuição do vírus para todo o organismo. Não estão totalmente esclarecidos os sítios de replicação viral no homem, mas as evidências apontam para as células da linhagem monocítica-macrofágica de órgãos linfóides, pulmões e fígado como os principais locais. ${ }^{9}$

A replicação viral estimula os monócitos e, indiretamente, linfócitos a produzirem citocinas. Algumas delas vão ter efeito pró-inflamatório e vão ser responsáveis pelo aparecimento de sintomas como a febre. Outras estimulam a produção de anticorpos, que se ligam aos antígenos virais formando imunocomplexos. ${ }^{1}$

Os anticorpos IgM antidengue começam a ser produzidos a partir do quinto e sexto dia. ${ }^{10}$ Eles são capazes de neutralizar o vírus de forma que seu aparecimento marca o declínio da viremia. Permanecem detectáveis no soro por aproximadamente dois meses. ${ }^{11}$

Os anticorpos IgG antidengue surgem após um período de sete a 10 dias de evolução ${ }^{10}$, sobem muito na convalescença e voltam a cair, persistindo em títulos baixos por toda a vida, conferindo imunidade sorotipo específica. Na infecção secundária, devido os linfócitos de memória, a produção de IgG começa mais precocemente e atinge níveis mais elevados. ${ }^{10,12}$

\section{Período de Incubação}

O período de incubação é de 3 a 15 dias $^{5}$, com média de 4 a 7 dias. $^{12}$

\section{Aspectos clínicos}

A infecção pelo vírus da dengue pode ser desde assintomática até ocasionar doença grave que coloque em risco a vida do paciente. Fatores relacionados tanto ao vírus quanto ao hospedeiro determinam a gravidade. Á seguir, estão relacionados alguns deles: - Vírus: existe a hipótese de que determinados genótipos do vírus seriam mais virulentos ${ }^{14} \mathrm{e}$, assim, infectariam maior número de células propiciando proliferação viral em alta escala e aumento da viremia, o que resultaria em ativação mais potente do sistema imunológico e resposta inflamatória intensa, permitindo o desenvolvimento de formas mais graves da doença. ${ }^{1}$ Essa hipótese pode ser reforçada pelo fato de que a maior parte dos casos de febre hemorrágica da dengue observados nas Américas ter sido associado ao sorotipo DEN-2. ${ }^{14}$ Ela também pode explicar os casos isolados de febre

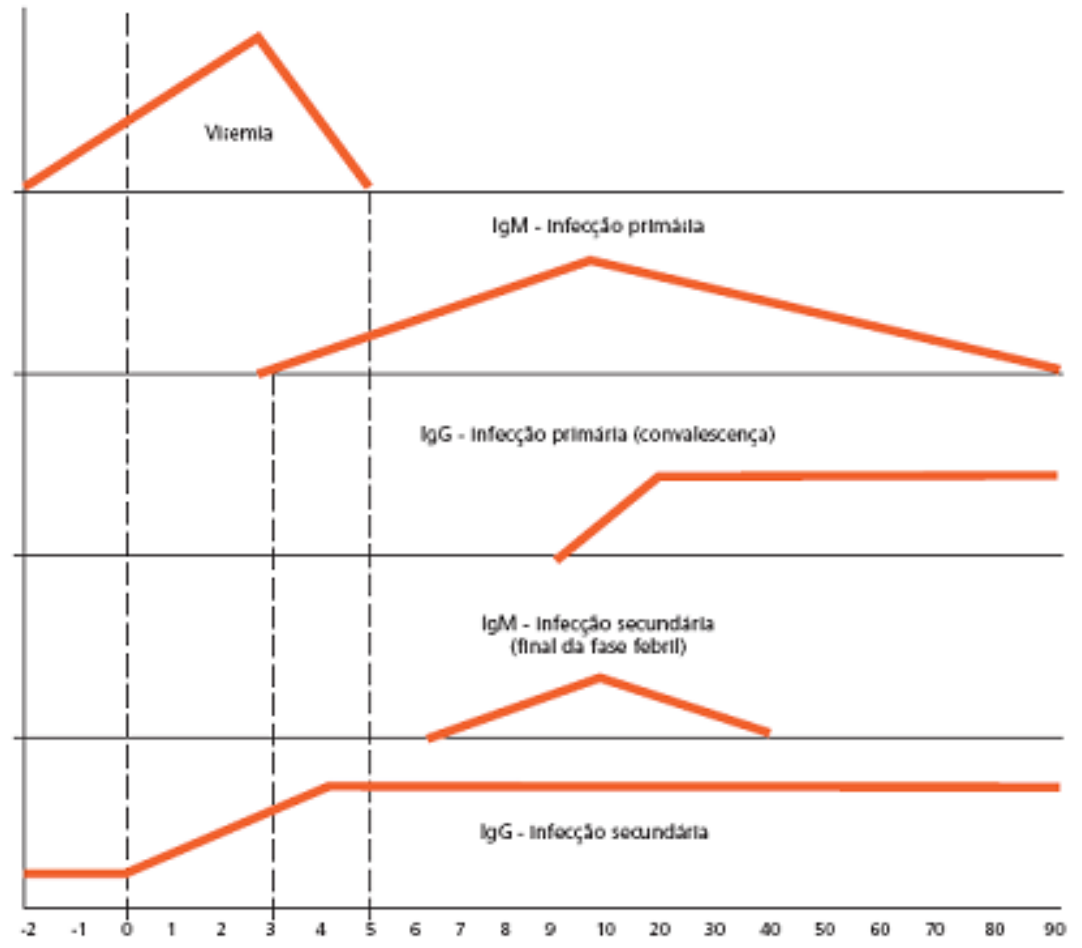

Dia de evoluço

Figura 1. Comportamento da viremia e da resposta imune (primária e secundária) na infecção pelo vírus da dengue. Fonte: Ministério da Saúde. Dengue, roteiro para capacitação de profissionais médicos no diagnóstico e tratamento - Manual do monitor. Brasília, $2007^{13}$. 
hemorrágica da dengue que ocorrem durante infecção primária, que provavelmente são consequência de infecção por cepas mais virulentas. ${ }^{11}$

- Infecção primária $\mathrm{x}$ infecção secundária: $\mathrm{O}$ risco de doença grave na infecção secundária é maior do que na infecção primária. Isso ocorre porque na infecção primária o paciente produz anticorpos que são neutralizantes para o sorotipo específico dessa infecção (imunidade homóloga) e que vão permanecer por toda a vida. ${ }^{15}$ Porém, esses anticorpos vão conferir proteção contra os outros sorotipos (imunidade heteróloga) por apenas alguns meses (três a seis meses). Depois desse período, se o paciente for infectado por sorotipo de vírus diferente daquele que ocasionou a infecção primária, esses anticorpos ligam-se ao vírus, mas não conseguem neutralizá-lo. Conforme defendido por Halsted ${ }^{16} \mathrm{em}$ sua teoria, essa ligação do anticorpo subneutralizante acaba facilitando, por meio de mecanismo de opsonização, a entrada do vírus na célula, fazendo com que uma quantidade maior de vírus ganhe o interior dos fagócitos. ${ }^{16}$

- Idade: O risco de febre hemorrágica da dengue diminui com o aumento da idade, principalmente após os 11 anos. Em regiões endêmicas, o maior risco de FHD ocorre entre seis e 12 meses de idade. Isso porque durante a gestação, se a mulher já tiver sido infectada pelo vírus da dengue, ela passa para o feto, por via transplacentária, anticorpos IgG antidengue. Entretanto, como esses anticorpos foram adquiridos de forma passiva, a tendência é que após o nascimento da criança eles vão declinando até chegar a níveis subneutralizantes. Então, caso essa criança seja infectada pelo vírus da dengue, mesmo que seja com o mesmo sorotipo que infectou sua mãe e mesmo na infecção primária, ela poderá ter FHD. ${ }^{17,18}$

- Estado Nutricional: Estudo feito com crianças tailandesas mostrou que a FHD é mais frequente em crianças eutróficas do que em crianças desnutridas. ${ }^{19}$ Isso pode estar relacionado à supressão da imunidade celular na desnutrição.

- Fatores Genéticos: Estudo realizado em Cuba mostrou que a FHD ocorre mais em brancos do que em negros $^{20}$, levantando a suspeita de que fatores genéticos, que ainda não estão bem esclarecidos, também estejam envolvidos na determinação da gravidade da doença.

Alguns pacientes infectados pelo vírus da dengue podem persistir assintomáticos ou terem doença febril indiferenciada. Isso ocorre principalmente em crianças menores de 15 anos. Em estudo feito com crianças na zona rural da Tailândia, 53\% das infecções pelo vírus da dengue não foram associadas com sintomas, apesar da intensa vigilância. ${ }^{21}$

As principais formas clínicas da dengue são a Dengue Clássica (DC), a Dengue com Complicações (DCC) e a Febre Hemorrágica da Dengue (FHD), podendo evoluir para a forma mais grave que é a Síndrome do Choque da Dengue (SCD).

A Dengue Clássica ou Febre da dengue se caracteriza por febre alta de início súbito (primeiro sintoma) acompanhada de manifestações como: cefaléia, dor retro-orbitária, prostração, mialgia intensa (o que justifica a sinonímia da doença de "febre quebraossos"), artralgia, anorexia, náuseas, vômitos, exantema e prurido cutâneo. ${ }^{12,22}$ Essa forma da doença é autolimitada, durando cinco a sete dias, apesar de a prostração poder persistir por semanas após o desaparecimento da febre. ${ }^{5}$

A erupção cutânea (rash) quando ocorre (é mais frequente nas infecções primárias do que nas secundárias) surge dois a cinco dias após o início da febre, é macular ou maculopapular, confluente (deixando eritema difuso entremeado por áreas de pele sadia) e pode ser pruriginoso. ${ }^{23}$

Manifestações hemorrágicas podem ocorrer nessa forma da doença e acontecem com relativa frequência, apesar de apenas em raros casos trazerem risco de morte ao paciente. Podem ser espontâneas, como epistaxe, gengivorragia, petéquias e metrorragia; ou provocadas, como prova do laço positiva. ${ }^{22}$ Essa prova é realizada desenhando-se no antebraço do paciente um quadrado com $2,5 \mathrm{~cm}$ de lado (ou uma área ao redor da falange distal do polegar). Em seguida deve-se verificar a pressão arterial do paciente (sentado ou de pé) e calcular o valor médio (PAS + PAD)/2. Então, deve-se insuflar novamente o manguito até atingir o valor médio e manter por cinco minutos. Depois é feita a contagem do número de petéquias que apareceram dentro do quadrado. A prova é considerada positiva se houver 20 ou mais petéquias. Deve-se ter em mente que essa prova também pode ser positiva em outras situações clínicas que cursem com fragilidade microvascular ou plaquetopenia. ${ }^{22}$

Os principais achados laboratoriais são leucopenia e plaquetopenia (que não costuma ser muito intensa). Elevação de transaminases também pode ocorrer. Geralmente o aumento é moderado (duas a cinco vezes acima do limite da normalidade), mas ocasio- 
nalmente pode ser mais acentuado (cinco a 15 vezes o limite da normalidade). ${ }^{24}$

É sempre importante diferenciar os casos de DC que cursam com manifestações hemorrágicas ou plaquetopenia de febre hemorrágica da dengue.

A Febre Hemorrágica da Dengue (FHD), também chamada de dengue hemorrágica, é a forma mais grave da doença. Caso não tenha diagnóstico precoce e tratamento médico adequado e em tempo hábil, pode evoluir com choque circulatório, situação essa que passa a ser chamada de Síndrome do Choque da Dengue (SCD), que está associada à elevada taxa de mortalidade.

Conforme estabelecido pela OMS, todo paciente com dengue necessita ter os quatro critérios abaixo para que a doença possa ser classificada como FHD $^{25}$ :

- febre ou história de febre recente de até sete dias;

- trombocitopenia (contagem plaquetária $<100.000 /$ $\left.\mathrm{mm}^{3}\right)$;

- tendências hemorrágicas evidenciadas por um ou mais dos seguintes sinais: prova do laço positiva, petéquias, equimoses ou púrpuras, sangramentos de mucosas do trato gastrointestinal e outros;

- extravasamento de plasma devido ao aumento da permeabilidade capilar, manifestado por: hematócrito apresentando aumento de $20 \%$ sobre o basal na admissão; queda do hematócrito em $20 \%$ após tratamento adequado; ou presença de derrame pleural, ascite e hipoproteinemia.

O extravasamento de plasma é a manifestação mais específica da FHD, já que está presente apenas nessa forma clínica da doença, e é também o que põe em risco a vida do paciente, pois quando ocorre de forma muito intensa pode levar ao choque circulatório, que é de rápida instalação e se não for prontamente tratado pode levar ao óbito em 12-24 horas. ${ }^{25}$

Os fatores que propiciam o desenvolvimento da FHD (já descritos anteriormente) estão relacionados à viremia mais acentuada, o que amplifica a cascata de citocinas e ativação do complemento, causando disfunção endotelial, destruição plaquetária e consumo dos fatores da coagulação. Estas alterações são as responsáveis pelo aumento da permeabilidade vascular com extravasamento de plasma e, pelas manifestações hemorrágicas, que podem ter gravidade variável nessa forma da doença. ${ }^{26,27}$

Em sua fase inicial, a FHD é semelhante à dengue clássica. $\mathrm{O}$ agravamento se dá entre o terceiro e sétimo dia de evolução, que coincide com o desaparecimento da febre e é justamente quando acontece o extravasamento de plasma, com surgimento das alterações hemodinâmicas e manifestações hemorrágicas. ${ }^{24} \mathrm{Na}$ maior parte dos pacientes essa fase é precedida por sinais e sintomas que são, portanto, considerados como de alarme, prevendo a possibilidade de evolução desfavorável. ${ }^{28}$ (Tabela 1)

\section{Tabela 1}

Sinais de alarme na dengue

a) dor abdominal intensa e contínua;

b) vômitos persistentes;

c) hipotensão postural;

d) hipotensão arterial;

e) pressão diferencial < $20 \mathrm{mmHg}$ (PA convergente);

f) hepatomegalia dolorosa;

g) hemorragias importantes (hematêmese e/ou melena);

h) extremidades frias, cianose;

i) pulso rápido e fino;

j) agitação e/ou letargia;

k) diminuição da diurese;

1) diminuição repentina da temperatura corpórea ou hipotermia;

m) aumento repentino do hematócrito;

n) desconforto respiratório.

A FHD é classificada pela OMS, de acordo com sua gravidade, em quatro graus. ${ }^{25}$ (Tabela 2)

\section{Tabela 2}

Classificação da FHD, segundo a OMS, de acordo com a gravidade

Grau I: Febre acompanhada de sintomas inespecíficos, em que a única manifestação hemorrágica é a prova do laço positiva.

Grau II: Além das manifestações do grau I, ocorrem hemorragias espontâneas leves (sangramentos de pele, epistaxe, gengivorragia e outros)

Grau III: Colapso circulatório com pulso fraco e rápido, estreitamento da pressão arterial ou hipotensão, pele pegajosa e fria, e inquietação.

Grau IV ou Síndrome do Choque da Dengue: Choque profundo com ausência de pressão arterial e pressão de pulso imperceptível. 
Laboratorialmente, obrigatoriamente devem ser encontrados nessa forma da doença, como já citado, plaquetopenia $\left(<100.000 / \mathrm{mm}^{3}\right)$ e hemoconcentração. Podem também ocorrer: leucopenia, aumento das transaminases e alteração nas provas de coagulação (como alargamento do TP e TTPa e redução do fibrinogênio sérico).

Alguns pacientes com dengue podem ter manifestações menos usuais, como falência hepática (apesar de ser documentada principalmente após reversão de choque, podendo estar mais relacionada à hipotensão prolongada do que ao efeito direto do vírus), miocardiopatia, manifestações e síndromes neurológicas (delírio, depressão, sonolência, irritabilidade, coma, psicose, encefalite, convulsões, mononeuropatias, polineuropatias, Síndrome de Guillain-Barré, Síndrome de Reye, mielite transversa). ${ }^{29,30}$ Podem surgir no decorrer do período febril ou mais tardiamente, na convalescença.

É chamado dengue com complicações (DCC) todo caso de dengue que não se enquadra nos critérios da OMS de FHD, mas que não é classificada apenas como dengue clássica devido à presença de complicações caracterizadas por um dos achados a seguir: alterações graves do sistema nervoso; disfunção cardiorrespiratória; insuficiência hepática; plaquetopenia igual ou inferior a $50.000 / \mathrm{mm}^{3}$; hemorragia digestiva; derrames cavitários; leucometria global igual ou inferior a $1.000 / \mathrm{mm}^{3}$; óbito. ${ }^{22}$

\section{Diagnóstico Diferencial}

Considerando-se que a dengue tem amplo espectro clínico, as principais doenças que fazem diagnóstico diferencial são: influenza, enteroviroses, doenças exantemáticas (sarampo, rubéola, parvovirose, eritema infeccioso, mononucleose infecciosa, exantema súbito, citomegalovirose e outras), hepatites virais, hantavirose, pneumonia, sepse, infecção urinária, meningococcemia, leptospirose, malária, febre amarela. Outros agravos podem ser considerados conforme a situação epidemiológica da região. ${ }^{22}$

\section{Confirmação Diagnóstica}

Clinicamente, conforme determinação da vigilância epidemiológica, deve ser considerado como caso suspeito de dengue clássica todo paciente que apresente febre com duração máxima de sete dias acompanhada de duas ou mais das seguintes manifesta- ções: cefaléia, dor retro-orbitária, artralgia, mialgia, prostração, erupção cutânea; e que resida ou tenha estado nos últimos 15 dias em zona de circulação do vírus da dengue. $^{22}$

Se o paciente que era suspeito de dengue clássica apresentar também os 4 critérios definidos pela OMS para FHD citados anteriormente, ele passa a ser caso suspeito de FHD. ${ }^{22}$

Todo caso suspeito precisa ser notificado ao serviço de Vigilância Epidemiológica do município, pois a dengue é doença de notificação compulsória.

A confirmação do diagnóstico pode ser feita por meio de testes sorológicos ou de detecção viral, sendo os primeiros os mais utilizados e estando os de detecção virais mais reservados para quando se tem propósito epidemiológico ou como parte de pesquisa para estudos clínicos. ${ }^{31}$

Todavia, para a vigilância epidemiológica, os casos suspeitos de DC identificados durante períodos de epidemia podem, apenas por critério clínico-epidemiológico, já ser considerados confirmados, exceto em gestantes, quando a sorologia deve ser sempre colhida. Já os casos suspeitos de DC fora de períodos de epidemia e todo caso grave ou suspeito de FHD (independente do período), precisam ser confirmados laboratorialmente. ${ }^{22}$

Os testes sorológicos identificam na amostra de soro examinada a presença de anticorpos contra o vírus da dengue. Em geral, eles só podem ser realizados a partir do sexto dia de doença, quando esses anticorpos começam a surgir, de forma que possuem maior importância epidemiológica do que clínica; e, além disso, não conseguem identificar o sorotipo do vírus envolvido na infecção. As técnicas disponíveis são: inibição da hemaglutinação (IH), fixação do complemento (FC), teste de neutralização (TN) e ensaio imunoenzimático (ELISA). ${ }^{22}$

O exame mais empregado é o MAC-ELISA, que detecta anticorpos IgM específicos contra a dengue. Sua grande vantagem é exigir uma única amostra de soro. ${ }^{31}$ Pode ser realizado a partir do sexto dia de sintomas e permanece positivo por 30 a 90 dias. ${ }^{11}$

Testes imunocromatográficos estão sendo desenvolvidos para serem realizados como exames de triagem, já que o resultado é disponibilizado mais rapidamente. Entretanto, seus resultados precisam ser confirmados por técnicas mais sensíveis.

Para detecção viral pode-se realizar isolamento do vírus, imunohistoquímica e reação em cadeia da polimerase (PCR). 
Imunohistoquímica pode ser usada para detecção de antígenos virais no fígado, baço, pulmões e linfonodos, sendo que os melhores resultados foram obtidos em fígado. ${ }^{10}$ Entretanto, como biópsia desses órgãos é raramente indicada em pacientes com suspeita de infecção pelo vírus da dengue, esse método é geralmente usado somente para diagnóstico pós-morte.

$\mathrm{O}$ isolamento do vírus no sangue fornece confirmação definitiva de infecção e permite a identificação do sorotipo de vírus envolvido. Pode ser tentado até o sétimo dia de doença, apesar de ficar mais difícil o isolamento por volta do quarto ou quinto dia, quando surgem os anticorpos IgM. O resultado é fornecido em uma ou duas semanas e é necessário se ter muito cuidado com a manipulação da amostra colhida, pois diversos fatores influenciam a atividade viral. ${ }^{12}$

A RT-PCR (reverse transcriptase polymerase chain reaction) é o único método que pode detectar o vírus dentro de tempo clinicamente significativo (um a dois dias). Pode ser empregado para detectar o RNA viral em amostras clínicas, material de necropsia, culturas de tecido e mosquitos adultos ou larvas. Tem sensibilidade comparável ao do isolamento viral com a vantagem de o resultado não ser influenciado pelo manuseio e armazenamento inadequados e nem pela presença de anticorpos. ${ }^{32}$

\section{Tratamento}

Não existe tratamento específico para dengue sendo indicados a princípio, apenas sintomáticos e hidratação.

O protocolo que será descrito foi extraído de publicação do Ministério da Saúde. ${ }^{22}$ Ele foi criado com intuito de evitar o retardo no diagnóstico de formas graves de dengue e no seu tratamento, e propõe que todo paciente com suspeita da doença seja dividido em quatro grupos, de acordo com os achados da anamnese e do exame físico, orientando a conduta adequada a ser adotada em cada caso.

- Grupo A: Casos suspeitos de dengue com prova do laço negativa, sem manifestações hemorrágicas espontâneas e sem sinais de alarme.

Mesmo nesse grupo é recomendada a coleta de hemograma, que deve ser feita no mesmo dia podendo o resultado ser checado em até 24 horas. $\mathrm{O}$ tratamento consiste em: hidratação oral com volume de 60 a $80 \mathrm{ml} / \mathrm{Kg} / \mathrm{dia}$, sendo $1 / 3$ desse volume com soro de rehidratação oral e os $2 / 3$ restantes com líqui- dos caseiros como água, suco de frutas, chás, etc; e, sintomáticos, como analgésicos, antitérmicos, antieméticos e anti-histamínicos. Não devem ser utilizados salicilatos e anti-inflamatórios não hormonais devido ao risco de sangramento. $\mathrm{O}$ paciente deve ser orientado a retornar para reavaliação assim que houver o desaparecimento da febre (entre o segundo e sexto dia da doença), já que isso marca o início da fase crítica; ou, imediatamente caso apareçam sinais de alarme.

- Grupo B: Casos suspeitos de dengue com prova do laço positiva ou manifestações hemorrágicas espontâneas, sem repercussões hemodinâmicas. Sinais de alarme ausentes.

Nesses pacientes a coleta de hemograma é obrigatória e deve ser feita de imediato. O paciente deve permanecer na unidade de saúde, recebendo inicialmente hidratação oral e sintomáticos conforme descrito no grupo A, até que se tenha o resultado do hemograma, quando poderão ocorrer três situações:

- Hemograma normal: paciente poderá ser liberado para tratamento ambulatorial que deverá ser conduzido igual ao de um paciente do grupo A.

- Se for verificado hematócrito aumentado em até $10 \%$ acima do valor basal (ou, na ausência deste, hematócrito entre $40-44 \%$ para mulheres e $45-50 \%$ para homens) e/ou plaquetopenia entre $50-100.000 / \mathrm{mm}^{3}$ e/ou leucopenia $<1.000$ células $/ \mathrm{mm}^{3}$ : o tratamento também poderá ser ambulatorial, mas deverá ser feita hidratação oral vigorosa, com $80 \mathrm{ml} / \mathrm{Kg} / \mathrm{dia}$, além de sintomáticos. Esse paciente deverá retornar para reavaliação clínico-laboratorial em 24 horas, ou antes, se surgirem sinais de alarme e, nesse retorno, deverá ser re-estadiado.

- Se for verificado hematócrito aumentado em mais de $10 \%$ acima do valor basal (ou, na ausência deste, hematócrito $>44 \%$ para mulheres e $>50 \%$ para homens) e/ou plaquetopenia $<50.000 / \mathrm{mm}^{3}$ : paciente deverá ficar em observação por um período mínimo de 6 horas. Nesse período, realizar hidratação oral supervisionada ou parenteral, com infusão de $1 / 3$ do volume calculado para $80 \mathrm{ml} / \mathrm{Kg} /$ dia na forma de solução salina. Após isso, reavaliar o hematócrito. Se estiver normal, tratamento ambulatorial com hidratação oral vigorosa e retorno para reavaliação clínico-laboratorial em 24 horas. Se a resposta for inadequada, repetir a conduta e avaliar necessidade de internação hospitalar. 
Se surgirem sinais de alarme ou aumento do hematócrito na vigência de hidratação adequada, é indicada a internação hospitalar.

Pacientes com plaquetopenia $<20.000 / \mathrm{mm}^{3}$, mesmo sem repercussão clínica, devem ser internados e reavaliados clínica e laboratorialmente a cada 12 horas.

- Grupo C: Casos suspeitos de dengue com presença de algum sinal de alarme, podendo as manifestações hemorrágicas estar presentes ou ausentes.

Nesse grupo é obrigatório não apenas a coleta de hemograma como também de tipagem sanguínea, dosagem de albumina sérica, radiografia de tórax. Outros exames podem ser avaliados conforme a necessidade, como glicose, uréia, creatinina, eletrólitos, transaminases, gasometria arterial, ultrassonografia de abdome e de tórax. Esses pacientes deverão permanecer sob supervisão médica por um período mínimo de 24 horas.

Hidratação endovenosa deve ser imediatamente iniciada, com $25 \mathrm{ml} / \mathrm{Kg}$ de solução fisiológica ou ringer lactato em 4 horas. Reavaliar posteriormente. Se houver melhora clínica e laboratorial, iniciar etapa de manutenção, administrando inicialmente $25 \mathrm{ml} / \mathrm{Kg}$ em 8 horas e depois o mesmo volume em 12 horas. Se a resposta for inadequada, repetir a conduta inicial, o que pode ser feito por até três vezes, reavaliando ao final de cada etapa. Caso a resposta persista insatisfatória o paciente deverá ser tratado como os do grupo D.

- Grupo D: Casos suspeitos de dengue apresentando pressão arterial convergente, hipotensão arterial ou choque. Manifestações hemorrágicas podem estar presentes ou ausentes.

Os exames laboratoriais a serem colhidos são os mesmos indicados aos pacientes do grupo $\mathrm{C}$ e os pacientes deverão permanecer sob cuidados médicos por no mínimo 24 horas.

Deve-se iniciar hidratação parenteral com solução salina isotônica ( $20 \mathrm{ml} / \mathrm{Kg}$ em até 20 minutos) imediatamente. Se for necessário, repetir por até três vezes. Deve ser feita reavaliação clínica a cada 1530 minutos e colhido hematócrito após 2 horas do início do tratamento. Se houver melhora clínica (normalização da pressão arterial, do débito urinário, pulso e respiração), o paciente deve ser tratado como no grupo $\mathrm{C}$, sendo iniciada a etapa de manutenção da hidratação. Se a resposta for inadequada, avaliar a hemoconcentração:
- Hematócrito em ascensão e choque, após a hidratação adequada: utilizar expansores plasmáticos (colóides sintéticos - 10ml/Kg/h e, na falta deste, fazer albumina - $3 \mathrm{ml} / \mathrm{Kg} / \mathrm{h}$ ).

- Hematócrito em queda e choque: investigar hemorragias (e transfundir concentrado de hemácias, se necessário); coagulopatia de consumo e hiper-hidratação (tratando com diuréticos, se necessário).

Em ambos os casos, se a resposta for inadequada, encaminhar o paciente para unidade de terapia intensiva.

Não se deve realizar transfusão de concentrado de plaquetas apenas baseado na contagem plaquetária, já que a plaquetopenia ocorre principalmente por destruição periférica, e as plaquetas recebidas pelo paciente seriam destruídas em curto prazo. Ela poderá ser indicada se houver plaquetas $<50.000 / \mathrm{mm}^{3}$ com suspeita de sangramento do sistema nervoso central e em casos de plaquetas $<20.000 / \mathrm{mm}^{3}$ na presença de sangramentos importantes. Nesses casos, as plaquetas são transfundidas para tamponamento no local de sangramento e não para aumentar a contagem plaquetária.

Com a resolução do choque, há reabsorção do plasma extravasado com queda adicional do hematócrito, mesmo com suspensão da hidratação parenteral. Essa reabsorção poderá causar hipervolemia, edema pulmonar ou insuficiência cardíaca, requerendo vigilância clínica redobrada.

Os critérios para alta hospitalar são: ausência de febre por 24 horas sem uso de antitérmicos, melhora visível do quadro, hematócrito normal e estável, plaquetas em elevação e acima de $50.000 / \mathrm{mm}^{3}$, estabilidade hemodinâmica durante 24 horas, derrames cavitários em absorção e sem repercussão clínica.

\section{Prevençẽo}

Uma vacina eficaz para a dengue deveria fornecer imunidade simultânea e duradoura para os quatro sorotipos virais. Há várias linhas em pesquisa, porém nenhuma delas em fase de uso populacional.

Assim, a melhor forma de prevenção da doença continua sendo pelo controle do seu vetor. Para isso, é fundamental o esclarecimento da sociedade para que ela atue juntamente aos órgãos públicos, já que o principal local onde são encontrados os mosquitos da dengue são dentro dos domicílios. 


\section{ABSTRACT}

Dengue is an arbovirus transmitted mainly by the bite of the mosquito Aedes aegypti. It can be asymptomatic or present a wide clinical spectrum, ranging from self-limited febrile illness to severe forms that could evolve with circulatory shock and death. In order to avoid this outcome, early diagnosis of disease and the detection of warning signs that indicate unfavorable, as well as adequate treatment are essential, There is no specific treatment, it is only symptomatic and supportive. Up to now, there is no vaccine available for prevention of disease, vector control the most effective measure.

\section{Keywords: Dengue Hemorrhagic Fever. Dengue Virus. Flavivirus.}

\section{Referências Bibliográficas}

1. Fonseca BAL, Fonseca SNS. Dengue virus infections. Curr Opin Pediatr. 2002; 14:1, 67-71.

2. Rodhain F, Rosen L. Mosquito vectors and dengue virusvector relationships. In: Gubler DJ, Kuno G, eds. Dengue and Dengue Hemorrhagic Fever. Cambridge: CAB International; New York,1997, p. 45-60.

3. Fiocruz. Vetor da dengue na Ásia, A. albopictus é alvo de estudos. Disponível em: http://www.fiocruz.br/ioc/cgi/ cgilua.exe/sys/start.htm?infoid=576\&sid=32. Acesso em 22 de maio 2009.

4. Tan PC, Rajasingam G, Devi S, Omar SZ. Dengue infection in pregnancy: prevalence, vertical transmission, and pregnancy outcome. Obstet Gynecol. 2008;111(5):1111-7.

5. Ministério da Saúde do Brasil. Disponível em: http://portal. saude.gov.br/portal/saude/Gestor/visualizar_texto. cfm? idtxt=27630

6. Brasil. Ministério da Saúde. Secretaria de Vigilância em Saúde. Informe Epidemiológico da Dengue - Análise de Situação e Tendências - 2010. Disponível em: http://portal.saude. gov.br/ portal/arquivos/pdf/informe. Acesso em 03 de novembro 2010.

7. Westaway EG, Blok J. Taxonomy and evolutionary relationships of flaviviruses. In:Gubler DJ, Kuno C, eds. Dengue and Dengue Hemorrhagic Fever. Cambridge: CAB International; 1997, p. 147-73.

8. Brasil. Ministério da Saúde. Secretaria de Vigilância em Saúde. Nota Técnica. Disponível em: http://portal.saude.gov.br/ portal/arquivos/pdf/nt_aval_vul_epid_dengue. Acesso em 03 de novembro 2010.

9. Bhamarapravati N. Pathology of dengue infections. In: Gubler DJ, Kuno G, eds. Dengue and Dengue Hemorrhagic Fever. Cambridge: CAB International; 1997, p.115-32.

10. Guzmán MG, Kouri G. Dengue: an update. Lancet Infect Dis 2002;2:33-42.

11. Tsai TF,Vaughn D, Solomon T. Flaviviruses (Yellow Fever, Dengue Hemorrhagic fever, Japanese Encephalitis, St Louis Encephalitis, Tick-borne Encephalitis). In:Mandell G, Bennett J, Dolin R, eds. Principles and Practice of Infectious Diseases, 6th ed, Elsevier-Churchill-Livingstone, Philadelphia, 2005.

12. Gubler DJ. Dengue and dengue hemorrhagic fever. Clin Microbiol Rev 1998;11(3):480-496.
13. Brasil. Ministério da Saúde. Secretaria de Vigilância em Saúde. Dengue: roteiro para capacitação de profissionais médicos no diagnóstico e tratamento - Manual do monitor. $3^{a}$ edição. Brasília 2007.

14. Rico-Hesse R, Harrison LM, Salas RA, Tovar D, Nisalak A, Ramos $\mathrm{C}$, et al. Origins of dengue type 2 viruses associated with increased pathogenicity in the Americas. Virology 1997;230:244-251.

15. Sabin AB. Research on dengue during World War II. Am J Trop Med Hyg 1952;1:30-50.

16. Halstead SB. Pathogenesis of dengue: challenges to molecular biology. Science 1988; 238:476-81.

17. Kliks SC, Nimmanitya S, Nisalak A, Burke DS. Evidence that maternal dengue antibodies are important in the development of dengue hemorrhagic fever in infants. Am J Trop Med Hyg 1988;38(2):411-9.

18. Simmons CP, Chau TN, Thuy TT, Tuan NM, Hoang DM, Thien NT, et al. Maternal antibody and viral factors in the pathogenesis of dengue virus in infants. J Infect Dis 2007;196:416-24.

19. Thisyakorn U, Nimmannitya S. Nutritional status of children with dengue hemorrhagic fever. Clin Infect Dis. 1993;16:295-7.

20. Guzman MG, Kouri GP, Bravo J, Soler M, Vazquez S, Morier L. Dengue hemorrhagic fever in Cuba, 1981: A retrospective seroepidemiologic study. Am J Trop Med Hyg 1990;42:179-84.

21.Endy TP, Chunsuttiwat S, Nisalak A, Libraty DH, Green S, Rothman AL, et al. Epidemiology of inapparent and symptomatic acute dengue virus infection: a prospective study of school children in Kamphaeng Phet, Thailand. Am J Epidemiol. 2002;156:40-51.

22. Brasil. Ministério da Saúde. Secretaria de Vigilância em Saúde. Dengue: diagnóstico e manejo clinico: adulto e criança $2^{\underline{a}}$ edição. Brasília 2005.

23. Waterman SH, Gubler DJ. Dengue fever. Clin Dermatol. 1989;7:117-22.

24. Kalayanarooj S, Vaughn DW, Nimmannitya S, Green S, Suntayakorn S, Kunentrasai N, et al. Early clinical and laboratory indicators of acute dengue illness. J Infect Dis. 1997; $176: 313-21$

25. World Health Organization. Dengue haemorrhagic fever: diagnosis, treatment, prevention and control. Geneva, 1997. Disponível em: http://www.who.int/csr/resources/publications/dengue/Denguepublication/en/index.html. Acesso em 22 de maio 2009. 
26. Lei HY, Yeh TM, Liu HS, Lin YS, Chen SH, Liu CC. Immunopathogenesis of dengue virus infection. J Biomed Sci 2001;8:377-88.

27. Kurane I, Takasaki T. Dengue fever and dengue haemorrhagic fever: challenges of controlling an enemy still at large. Rev Med Virol. 2001;11:301- 11.

28. Rigau-Perez JG, Laufer MK. Dengue-related deaths in Puerto Rico, 1992-1996: diagnosis and clinical alarm signals. Clin Infect Dis. 2006;42(9)::1241-6.

29. Nimmannitya S, Thisyakorn U, Hemsrichart V. Dengue haemorrhagic fever with unusual manifestations. Southeast Asian J Trop Med Public Health 1987;18:398-406.
30. Solomon T, Dung NM, Vaughn DW, Kneen R, Thao LT, Raengsakulrach B, et al. Neurological manifestations of dengue infection. Lancet. 2000;355:1053-9.

31. Rigau-Perez JG, Gubler DJ, Vorndam AV, Clark GG. Dengue surveillance-United States, 1986-1992. MMWR CDC Surveill Summ. 1994; 43(2):7-19.

32. Sudiro TM, Ishiko $H$, Green $S$, Vaughn DW, Nisalak A, Kalayanarooj $\mathrm{S}$, et al. Rapid diagnosis of dengue viremia by reverse transcriptase-polymerase chain reaction using 3'noncoding region universal primers. Am J Trop Med Hyg 1997;56:424-9. 